\title{
"Evolution for Everyone": A Course that Expands Evolutionary Theory Beyond the Biological Sciences
}

\author{
Daniel Tumminelli O'Brien • David Sloan Wilson • \\ Patricia H. Hawley
}

Published online: 30 July 2009

(C) Springer Science + Business Media, LLC 2009

\begin{abstract}
A firm grasp of evolution is invaluable for understanding our own species in addition to the rest of the biological world; however, not only does much of the American public reject evolution, but many thinkers within the scientific community resist its application to their own disciplines. In an attempt to overcome these challenges through education, the Evolutionary Studies (EvoS) program at Binghamton University (B.U.) strives to present evolution as a theory relevant to all human-related subjects. Here, we present the cornerstone of this program, "Evolution for Everyone," an introductory-level, general education course with an academically diverse student population. The curriculum delves into Darwin's theory and uses it to illustrate not only classical biology but how the same ideas pertain to the full range of human-related disciplines. This material is framed in terms of scientific inquiry, including direct participation in research. An evaluation of the course has demonstrated that it increases both understanding and acceptance of evolution and its relevance to human-related academic disciplines and everyday life. The EvoS program has received National Science Foundation funding to
\end{abstract}

\footnotetext{
D. T. O’Brien $(\bowtie) \cdot$ D. S. Wilson

Department of Biology,

Binghamton University (State University of New York),

Binghamton, NY 13902-6000, USA

e-mail: Dobrien1@binghamton.edu

D. S. Wilson

Department of Anthropology,

Binghamton University (State University of New York),

Binghamton, NY 13902-6000, USA

P. H. Hawley

Department of Psychology, University of Kansas,

Lawrence, KS 66045-7556, USA
}

expand into a nationwide consortium, providing a strong infrastructure for the development of similar courses at other institutions.

Keywords Evolution education · Interdisciplinary approaches · Culture of evolution · Attitudes toward evolution

Darwin's theory of evolution is the most powerful explanatory and predictive tool available for the study of living things, a realization that has been under attack from conservative religious groups for over a century (Numbers 2006). The resurgence of this public debate has had profound effects in the USA, where a recent survey found that only about $40 \%$ of Americans agree with the statement "human beings, as we know them, developed from earlier species of animals" (Miller et al. 2006). Of even more concern, the cultural movement that has produced this nonscientific worldview in America has also been gaining strength in other countries in recent years (see PACE 2009 for a summary of such events in Europe).

While this ideological conflict about human origins is ongoing in society as a whole, there is also a divide within academia as to the theory's applicability to human research. Some take the stance that evolutionary theory should inform all behavioral studies, be the focus on individuals or societal institutions (Gintis 2007; Wilson 2007). Such an approach has been embraced by prominent thinkers within the social sciences, including psychologists (Buss 2004; Dunbar et al. 2005; Pinker 2002), economists (Bowles 2006; Gintis et al. 2005), philosophers (Buller 2006; Haidt 2006), and anthropologists (Boehm 2001; Henrich et al. 2007). Nevertheless, evolution is still taught primarily as a subject in the biological sciences, rather than a theory that can help to unify the human-related disciplines. 
Despite this lack of consensus, when attempting to formulate an opinion on evolution, Americans are still most interested in the stances of scientists and science teachers (CSS 2009). The challenge then falls to educators to create courses that stress both the mechanisms and the relevance of evolution. Evidence suggests that the simplest way to do so is to make evolutionary theory a prominent feature in the curriculum. In a sample of entering freshmen at the University of Minnesota, those who recalled a stronger focus on evolution in their high school biology classes reported greater acceptance of the theory (Moore and Cotner 2009). Similarly, college students at the University of Kansas who reported a greater level of training in and exposure to evolutionary theory tended to view it more positively (Hawley et al. 2009). In addition to the theory itself, a strong classroom focus on the scientific process may further facilitate evolution education: both students (Lombrozo et al. 2008; Verhey 2005; Woods and Scharmann 2001) and high school biology teachers (Rutledge and Mitchell 2002; Scharmann and Harris 1992) who are well acquainted with the scientific method are more likely to be accepting of evolutionary theory.

Binghamton University's (B.U.) EvoS (for Evolutionary Studies, pronounced as one word) program is a comprehensive effort to teach evolution as part of a scientific approach to all human-related subjects in addition to the biological sciences (Wilson 2005, 2007). Initiated in 2003, it is now becoming the basis of a nationwide consortium of programs funded by the National Science Foundation (http://www.evostudies.org/) that currently includes groups from over 35 institutions. A cornerstone of an EvoS program is an introductory "Evolution for Everyone" course that immerses students from all backgrounds and academic disciplines in both evolutionary theory and the scientific process. Here, we describe the course that has been developed at Binghamton, which includes the following features:

- A large lecture course that provides students from any background with a firm knowledge of the mechanisms of evolution.

- A strong focus on the application of evolutionary theory to human affairs.

- A curriculum that is structured to highlight the scientific process, its steps, and proper use. This includes both inclass experiments and a final project that requires the students to propose novel research.

- A before-and-after assessment that demonstrates a positive effect on both the students' knowledge of evolution and their attitudes towards its relevance.

- A centralized bank of educational materials designed to facilitate similar courses elsewhere, as well as coordinated teaching of such courses across institutions.

\section{The Course}

Background and Primary Goals

B.U.'s version of "Evolution for Everyone" is a large (approximately 200 students) introductory-level biology course that has no prerequisites and satisfies general education requirements. In addition to weekly lectures, students also attend smaller weekly discussion sections in which activities are run by undergraduate teaching assistants. The course is cross-listed by the biology and anthropology departments, reflecting its emphasis on both biological and human-related topics. Although a 100-level course, it has become popular among students from all grade levels and a diverse range of majors (see Table 1).

The initial format involved teaching the basic principles of evolution during the first part of the course, which were then applied to a diversity of biological and human-related subjects during the rest of the course (Wilson 2005). This format became the basis of a book by the same name

Table 1 Demographic information for entry survey participants (and participants in both surveys)

\begin{tabular}{|c|c|c|}
\hline & Number & Percentage \\
\hline \multicolumn{3}{|l|}{ Gender } \\
\hline Male & $88(60)$ & $52 \%(50 \%)$ \\
\hline Female & $80(60)$ & $48 \%(50 \%)$ \\
\hline \multicolumn{3}{|l|}{ Class level } \\
\hline Freshman & $58(44)$ & $35 \%(37 \%)$ \\
\hline Sophomore & $50(37)$ & $30 \%(31 \%)$ \\
\hline Junior & $43(27)$ & $26 \%(23 \%)$ \\
\hline Senior & 15 (12) & $9 \%(10 \%)$ \\
\hline Non-matriculated & $2(1)$ & $1 \%(<1 \%)$ \\
\hline \multicolumn{3}{|l|}{ Academic division $^{\mathrm{a}}$} \\
\hline Biological sciences & $29(22)$ & $17 \%(18 \%)$ \\
\hline Social sciences & $65(52)$ & $39 \%(43 \%)$ \\
\hline Humanities & $11(9)$ & $7 \%(9 \%)$ \\
\hline Hard sciences & $16(10)$ & $10 \%(13 \%)$ \\
\hline Undeclared & $53(34)$ & $32 \%(28 \%)$ \\
\hline \multicolumn{3}{|l|}{ Religion $^{\mathrm{b}}$} \\
\hline Christian $^{\mathrm{c}}$ & $65(46)$ & $39 \%(38 \%)$ \\
\hline Jewish & $40(34)$ & $24 \%(28 \%)$ \\
\hline Agnostic/atheist & $38(23)$ & $23 \%(19 \%)$ \\
\hline Other/undeclared & $25(18)$ & $15 \%(15 \%)$ \\
\hline
\end{tabular}

${ }^{\text {a }}$ Seven majors in psychobiology were categorized as both members of the biological and social sciences. Six of these participated in the exit survey

${ }^{\mathrm{b}}$ One individual participating in both surveys reported being both Catholic and Jewish and was included in both categories

${ }^{\mathrm{c}}$ Christians included in both populations were primarily Roman Catholic (70\%) but also included two Lutherans, two Methodists, and one Scientologist. The rest did not declare a specific denomination 
(Wilson 2007), which is now used as the textbook with supplementary reading from the primary literature.

Packaging the original material as an easily read book enabled us to be even more ambitious in our learning goals for the course. The current format succeeds at teaching the basic principles of evolution and how they are easily applied to human studies. Simultaneously, it gives the students the skills of scientific inquiry, including a strong grasp of scientific methods and basic statistics. This is accomplished in part by modeling the course structure around scientific methodology (discussed in greater detail below). Finally, it has been organized to be easily taught in a coordinated fashion across institutions.

\section{Teaching the Basic Principles of Evolution}

The course opens with a description of natural selection as a simple algorithm with powerful implications: (a) individuals in a population with diverse traits will often have differential reproductive success; (b) many traits are heritable; (c) therefore, traits that enhance reproductive success will be more highly represented in the next generation. Empirical evidence suggests that students absorb an abstract concept like this one more fully if they are given the opportunity to engage actively with its application (see Gardiner 1998 for a review). Therefore, immediately after introducing the concept of natural selection, we therefore ask the students to reason on the basis of natural selection by asking them to predict how an apparently paradoxical behavior such as infanticide might evolve. The students reliably identify the three major environmental contexts for the evolution of infanticide (lack of resources, offspring quality, uncertain parentage), thereby providing an impressive demonstration of the power of evolutionary theory to make predictions about the traits of organisms - not just for infanticide but for innumerable traits in all species (see Wilson 2007, ch. 3).

Already apprentices in natural selection and its application, the students are ready to engage more deeply with the mechanisms of evolution. This portion of the course is not particularly different from any other evolution-based course. We begin with the history of Darwin's theory and how it serves to explain both the currently observable diversity of species as well as their history in the fossil record. We then proceed through the concepts of sexual selection, genetic drift, and descent with modification within the first few weeks. The remainder of the first section of the course is spent showing how traits are shaped by various evolutionary forces. This begins with a simple treatment of the genome and its operation, including interactions with external stimuli, resulting in phenotypic plasticity that is appropriately tailored to the environment. The section concludes with discussions of co-evolution and the evolution of social behavior. During each of these lectures, some time is dedicated to an activity that facilitates student engagement while helping to illustrate the main topic of the day, much like the infanticide example above. Another asks students to consider the oft-ridiculed tendency of lemmings to run almost blindly in a given direction and what environmental settings would make it adaptive. A lecture dedicated to sexual selection begins with the students describing differences between males and females and deciding which of these seems to be the "root difference." The goal is for them to arrive at the conclusion that differences in parental investment, beginning with the relative size of male and female gametes, have influenced the evolution of other morphological, behavioral, and life history traits in each sex. By the end of this section of the course, the students have a good working knowledge of evolutionary theory, including both proximate and ultimate causation and an emphasis on both the adaptive and nonadaptive sides of the evolutionary coin (as stressed by Gould and Lewontin 1979).

\section{Extending Evolution to Human Affairs:}

The "Modular" Phase

During the first part of the course, it is repeatedly noted that evolutionary theory and a scientific approach are valuable when trying to understand all species, including humans. The validity of this statement becomes increasingly apparent to the students as they become more acquainted with the theory itself and are exposed to a diversity of examples discussed in lecture and the reading. Many of these examples are human oriented, but it is not until the second phase of the course that we fully apply evolutionary theory to human affairs. At this time, we begin to discuss specific topics from an evolutionary perspective in modules that last between one and two weeks.

We begin with an initial module on human evolution, including lectures on primate history and cultural evolution. We then proceed to topics such as economics, medicine, personality, political institutions, and recreation. Because so many human-related subjects can be approached from an evolutionary perspective, we allow the students to help determine the choice of modules. They also choose their own topic to study independently, as outlined in more detail below.

Each module has its own specific structure, but they also share a number of features. We will use the module on economics as an example; other modules are represented in less detail in Table 2. First, the topic is generalized as part of an evolutionary question that is relevant to all organisms in relation to their environment. In the economics module, the subject is broadened to one of resource acquisition, leading to a discussion of optimal foraging theory and game 
theory in non-human species. These frameworks and associated findings are then synthesized to show how the same rules underlie the resource-oriented behaviors of humans, giving the students the ability to observe the operation of economic systems from an evolutionary perspective. It is important to note that, as this is not an economics class, we do not teach the material that would be presented in one. Instead, we illustrate how evolutionary models can be used to understand human behavior while in economic settings.

Lectures are supplemented with articles from the primary literature illustrating both human and non-human examples. The articles chosen are short and clearly written, making them easily accessible to the students, despite the fact that many of the students are encountering evolution for the first time or are from disciplines that provide little science training. A fascinating example in nonhumans is the sophisticated economic behavior that cleaner fish display toward their "clients," which is described by Bshary and Noë (2003) as a "biological market." An example for humans is a recent Science article by Bowles (2008) showing how economic policy predicated on the assumption of self-interest can fail when people have a more complex set of social preferences that can be discerned on the basis of evolutionary game theory.

Whenever possible, modules include an illustrative experiment that is performed in class or during the discussion sections, with the students acting as the participants. For the economics module, they play a twoperson sequential prisoner's dilemma game that illustrates the costs and benefits of cooperation. Specifically, the second player gets to choose to cooperate or defect based on the first player's prior choice. Because players will be paired anonymously and the roles will be randomized, the students need to make three decisions: how to play as a first mover; how to respond to a cooperator; and how to respond to a defector. The game is played twice, both with and without the ability to punish defecting partners (at a cost to oneself). The various components of the game measure variables such as trust, reciprocity and self-sacrifice, along with how these variables change when punishment is introduced. Within a week of the experiment, the results are incorporated into lecture, the data being quickly processed by a team of undergraduate students recruited from previous classes and working for independent study credits ("the research team," described in more detail below). In discussion section, the students are invited to develop hypotheses that associate these behaviors with the background variables collected in the course's entry survey (described in more detail below); the best of these are also presented in lecture. When appropriate, analyses are presented in class coupling this experiment's results to those of other class experiments, showing, for instance, how cooperative behaviors relate to the Big 5 personality factors (i.e., extraversion, 
conscientiousness, agreeableness, neuroticism, and openness to experience as first described by Thurstone 1934) or to aggressive behavior in adolescents.

Incorporating Scientific Methodology

In addition to teaching evolutionary theory and the value of its application, the course is also designed to make students fully comfortable with scientific inquiry. In fact, these two goals go hand in hand as researchers have found that one's attitudes toward evolution are closely related to understanding scientific methods (Lombrozo et al. 2008; Rutledge and Mitchell 2002; Woods and Scharmann 2001). Additional support comes from two other educational studies that improved attitudes about evolution. One increased acceptance of evolution in secondary school teachers through a workshop that focused on scientific theory and evolution (Scharmann and Harris 1992). The other placed evolutionary and Intelligent Design writings side by side in scientific debate (Verhey 2005), a controversial technique that resulted in some polarization but a net increase in acceptance of evolution.

For this reason, we structure the course itself around the scientific method. On the first day, the four main sections of a scientific paper are taught (introduction, methods, results, and discussion), which most students recall quickly from previous coursework. The twist, however, is that they are told that the semester itself will mirror that structure, and they are just entering the "introduction" section of the course. Thus, their initial exposure to the mechanisms by which evolution operates is treated as the background research appropriate to the opening of a paper. The modular phase of the course acts as the application of these ideas, both in theory and in practice, and is referred to as the "methods and results" section of the course. The course concludes with the "discussion" section, which will be described below.

While the evolution-oriented curriculum parallels the flow of a scientific paper, the course simultaneously educates the students in the skills appropriate to each section. During the introduction section, the steps required to formulate a coherent backdrop for a scientific study are first stated during lecture and then emphasized through weekly assignments. To illustrate, the students are taught in the first week that any study starts with a question. They are then asked to pick a topic about which they would like to ask the question, "How can this be better understood from an evolutionary perspective?" The following week, they are told to find abstracts from the primary literature that might inform their question. This assignment, dubbed "The Great Paper Chase," is obviously difficult for the students. For a week, the students are challenged to find their own methods for doing so, after which part of lecture is an introduction to the literature resources available through the B.U. library system. This inquiry eventually develops into the creation of novel hypotheses that are developed during subsequent stages of the course.

One focus during the first week of class is the distinction between the fact and theory of evolution (as described by Gould 1981). People have observed change in living populations for centuries. This has occurred directly through firsthand observations, such as the increased prevalence of black moths in Britain during the industrial revolution (Kettlewell 1955), and thousands of laboratory experiments. Change has also been witnessed indirectly by discovery of fossils belonging to species from long ago, many of which are now extinct. Theories that have been advanced to explain these observations have included the invention of zoocryptic creatures like dragons and griffins (Mayor 2001), Lamarck's theory of acquired traits (Lamarck 1809/1984), Intelligent Design (Davis and Kenyon 1993), and natural selection (Darwin 1859/2003). A scientific theory, though, must be capable of producing testable predictions, allowing researchers to either continue employing it or to disregard it in the future. As a framework for interpreting and understanding facts, a theory cannot suddenly be converted into a fact itself, making the measure of its value the consistency with which it is successful at answering questions of a given type. In the case of natural selection, although critics suggest that it can be brushed aside as "merely a theory," there is overwhelming evidence for its accuracy in explaining the fact of evolution. Communicating this to the students is immensely important in promoting the understanding and acceptance of evolution.

During the modules, we endeavor to present both methodological approaches and statistical skills. Rather than overwhelm the students with excessive information, we provide one of each during a given module, incorporating them into the associated experiment and analysis (see Table 2 for a list). The intention is to teach the students to conduct their own simple tests and to critically evaluate the methods and statistical results that they encounter in their readings. Students who become part of the undergraduate research team are trained more extensively in the scientific process as they clean datasets, calculate scores for survey scales (e.g., the Big 5), and perform some of the statistics necessary to represent the results.

What we refer to as the discussion section of the course is the final project that gives the students an opportunity to apply all of the skills they have learned over the course of the semester. Recall that earlier in the course they each chose a topic of interest, began exploring the primary literature, and developed evolutionarily informed hypotheses. Over the remainder of the semester, they are expected to continue researching and thinking about their topics to 
the point where they feel comfortable enough to craft their own experiment intended to test their novel hypotheses.

The students are not required to actually do the proposed research, but they present it in the form of posters during a class period at the end of the course that emulates a conference poster session, which is open to the campus community. Over the years, there have been many creative examples including: a synthesis of the evolutionary hypotheses attempting to understand male homoeroticism; how bird song is influenced by varying acoustics across habitats; and an analysis of how multiplayer online roleplaying games (e.g., World of Warcraft ${ }^{\circ}$ ) reflect the evolutionary roles of cooperation and selfishness.

\section{Evaluating the Course}

Methodology

To evaluate whether our course goals had been achieved, we assessed learner outcomes by way of the Evolutionary Attitudes and Literacy Survey (Hawley and Parkinson 2008) at the beginning and end of the fall 2009 "Evolution for Everyone" course. Of the 200 students enrolled in the course, 168 completed the survey at time one, 166 completed the survey at time two, but only 121 completed both times one and two. These discrepancies are in part due to the university's add-drop period which extends two weeks into the semester. Thus, the population of students registered for the class on the first and last days of the semester can be considerably different.

The initial draft of the survey employed here (cf. Hawley et al 2009) comprised six scales assessing various belief systems (e.g., religious), attitudes (e.g., about the relevance of evolutionary theory), and knowledge of biological topics (i.e., genetics). The scales were as follows: Young Earth Creationist Beliefs, Embryo/Fetus Beliefs (from Miller et al. 2006), Intelligent Design Fallacies, Social Objections to Evolution, Genetic and Evolutionary Literacy, and Relevance of Evolution (for items and scale reliabilities, see Table 3). The responses to each scale item were measured using a 7-point Likert scale from "strongly disagree" to "strongly agree," the center point (i.e., 4) representing "neither agree nor disagree."

In addition to assessing beliefs, knowledge, and attitudes, the survey assesses a wide range of background demographic information including political and religious activity and affiliations, intended major, class level, and experience with courses teaching evolution during high school (see Table 3). Individuals were classified according to religion and academic major (see Table 1). A collection of Christian denominations was represented in the class, but too few with numbers large enough to permit finer categorization in the statistical analyses. To address the range of ideologies associated with these different groups, an interaction between Christianity and one's score on the liberalism scale is included in all regression analyses (see below).

Time one of the survey was administered online, and the deadline for completion was before students were exposed to any course material to avoid any priming effect. The same survey (without the background and demographic variables) was administered online during the last week of class. To protect student anonymity, participants were identified with a self-chosen, eight-character ID code that was ultimately used to link time one with time two data. Though participation was completely voluntary, all students opted for the survey over the alternative assignment. Methods were approved by B.U.'s Institutional Review Board.

\section{Analysis}

The initial attitudes of the students (see Table 4 for descriptive statistics of the survey scales) were first analyzed in relation to background variables using regressions. A model was created for each scale that dealt directly with evolution (Social Objections, Factual Understanding, and Relevance). The models included numerous simple effects and some interactions (see Table 5 for the complete models). To assess how the course affected the beliefs of the students, paired $t$ tests between time one and time two were run for each of the six scales (visible in Table 6).

To test the relationship between changes in these scales and participants' backgrounds, we conducted two additional sets of regressions, each predicting the scores at time two. The first set of regressions used only background variables as predictors. These have been placed alongside the initial regressions in Table 5 so that the change in relationships between background variables and attitudes could be easily observed. The second set of models involved two steps. First, a regression was created using only the incoming score of the same scale as a predictor. Second, the background variables were added to the model (visible in Table 7). This methodology addresses whether individuals belonging to certain groups experienced greater or less change in attitudes than their peers. (Sixteen additional students left one of the predictor variables blank and were excluded from the regression analyses, making the sample size 105.)

Results

\section{The Entering Population}

The average individual entering the course was receptive to evolution and did not strongly support the tenets of Young 
Table 3 Questions and Cronbach's alphas for all scales in the evolution literacy survey

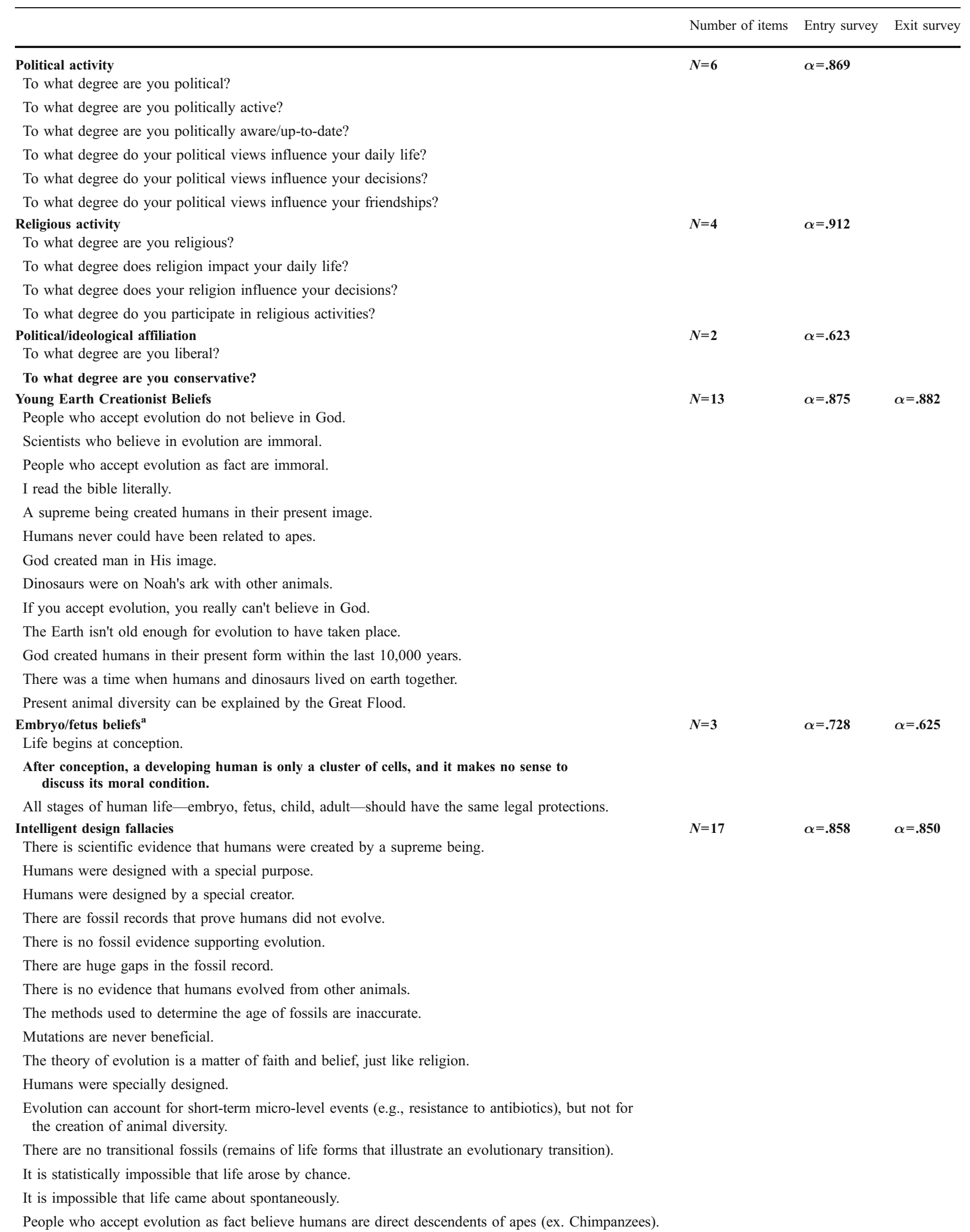


Table 3 (continued)

Number of items Entry survey Exit survey

The theory of evolution does not explain similarities or differences between chimps and humans.

Social objections to evolution

$N=6 \quad \alpha=.765 \quad \alpha=.753$

The theory of evolution has contributed to racism.

Applying the theory of evolution to human affairs implies we are not fully in control of our behavior.

The theory of evolution has contributed to sexism.

The theory of evolution has contributed to an increase in abortion.

The theory of evolution has contributed to genocide (the deliberate killing of a group based on nationality, race, politics, or culture).

The theory of evolution has contributed to an increase in euthanasia (the act of killing someone painlessly or allowing to die to stop the suffering; also called mercy killing).

Factual understanding of evolution

Humans share a majority of their genes with chimpanzees. ${ }^{\mathrm{b}}$

Humans share more than half of their genes with mice. ${ }^{\mathrm{b}}$

Ordinary tomatoes do not have genes, whereas genetically modified tomatoes do. ${ }^{b}$

Genetically modified animals are always larger than ordinary animals. ${ }^{b}$

Cloning is a form of reproduction in which offspring result from the union of sperm and egg. ${ }^{\text {b }}$

Today it is not possible to transfer genes from humans to animals. ${ }^{b}$

If someone eats a genetically modified fruit, there is a risk that a person's genes might be modified too.

All plants and animals have DNA. ${ }^{b}$

Today it is not possible to transfer genes from animals to plants. ${ }^{\mathrm{b}}$

Humans have somewhat less than half of the DNA in common with chimpanzees. ${ }^{b}$

You can see traces of our evolutionary past in human embryos.

Humans developed from earlier life forms.

Monkeys, apes, and humans look alike because they came from a common distant ancestor. ${ }^{\mathrm{c}}$

Different kinds of animals look alike because they came from a common distant ancestor. ${ }^{\mathrm{c}}$

Human behavior is influenced by our genes.

Relevance of evolution

The theory of evolution helps explain learning and culture.

$N=19 \quad \alpha=.928 \quad \alpha=.950$

The theory of evolution helps explain the world as it is in the present.

Genes are relevant to understanding the human body.

Evolutionary theory is highly relevant for botany.

Genes are relevant to understanding human behavior.

Evolutionary theory is highly relevant for zoology.

Evolutionary theory is highly relevant for biology.

Evolutionary theory is highly relevant for the social sciences (e.g., anthropology, psychology, sociology).

Evolutionary theory is highly relevant for the humanities (e.g., history, literature, philosophy).

For explaining human behavior, evolutionary theory is irrelevant.

Evolutionary theory is relevant to our everyday lives.

The theory of evolution is highly relevant to human affairs

The theory of evolution is irrelevant to human affairs.

The theory of evolution helps us understand plants.

The theory of evolution helps us understand animals.

The theory of evolution helps us understand animal behavior.

The theory of evolution helps us understand human origins.

The theory of evolution helps us understand human behavior.

The theory of evolution helps explain the world as it was in the past.

Cronbach's alphas are a measurement of the inter-correlation of all items in a scale (measured on a 0-1 scale). Boldfaced items are reverse coded (i.e., $1 \rightarrow 7,2 \rightarrow 6$, etc.) in order to maintain positive correlations between all scale items

${ }^{a}$ Attitude Toward Life Scale: from Miller et al. (2006)

${ }^{\mathrm{b}}$ Items drawn from Index of Genetic Literacy; Miller et al. (2006)

${ }^{\mathrm{c}}$ Items drawn from Spiegel et al. (2006) 
Table 4 Scores (and standard deviations) for the background and evolution literacy survey scales in the entering population (1-7 scale, $N=168$ )

\begin{tabular}{llll}
\hline Scale & Measurements & Scale & Measurements \\
\hline Political Activity & $3.17(2.27)$ & Intelligent Design Fallacies & $2.87(1.89)$ \\
Religious Activity & $2.87(2.47)$ & Social Objections to Evolution & $3.20(2.16)$ \\
Liberalism & $4.73(2.47)$ & Factual Understanding of Evolution & $5.42(1.81)$ \\
Young Earth Creationist Beliefs & $2.28(1.98)$ & Relevance of Evolution & $5.49(1.87)$ \\
Embryo/Fetus Beliefs & $3.90(2.87)$ & & \\
\hline
\end{tabular}

Earth Creationism and Intelligent Design (see Table 4 for complete measurements in the entry population). There was considerable variation around the mean, however, enabling a regression analysis and providing room for improvement on the basis of the course.

At the beginning of the semester, one's high school experience with evolution was positively associated with Factual Understanding $(\beta=.286, p<.001$; see Table 5$)$ and reports of evolution's Relevance $(\beta=.302, p<.001$; see Table 5), making it the most important predictor of evolutionary attitudes. This relationship confirms the results of other studies (Hawley et al. 2009; Moore and Cotner 2009). Additionally, individuals studying the physical sciences reported lower scores on the Relevance scale than others $(\beta=-.158, p<.05$; see Table 5$)$. Similarly, Paz-y-Miño and Espinosa (2009) found evolutionary attitudes to be lower in all non-biology majors, although they did not distinguish between the different divisions of academia.

Entering the class, Christians, Jews, and individuals scoring high on the liberalism scale reported fewer social objections to evolution (respectively $\beta=-.798, p<.05$; $\beta=-.785, p<.05 ; \beta=-.392, p<.05$; see Table 5). Interestingly, liberalism in Christians was found to be associated with more social objections $(\beta=.624, p<.05$; see Table 5$)$. These seemingly contradictory findings probably mean the

Table 5 Standardized betas (and semi-partial coefficients) for background variables predicting scale scores in the entry and exit populations

\begin{tabular}{|c|c|c|c|c|c|c|}
\hline & \multicolumn{2}{|l|}{ Social objections } & \multicolumn{2}{|c|}{ Factual knowledge } & \multicolumn{2}{|l|}{ Relevance } \\
\hline & Entry & Exit & Entry & Exit & Entry & Exit \\
\hline Class level & $-.001(-.001)$ & $.077(.064)$ & $.079(.067)$ & $.095(.079)$ & $.072(.061)$ & $.163(.136)$ \\
\hline Level of evolutionary training & $-.085(-.078)$ & $-.061(-.056)$ & $.286(.264)^{* * *}$ & $.122(.112)$ & $.302(.279)^{* * *}$ & $.076(.070)$ \\
\hline Political activity & $.045(.041)$ & $-.266(-.234)^{*}$ & $.075(.068)$ & $.356(.313)^{* * *}$ & $.146(.131)$ & $.278(.245)^{* *}$ \\
\hline Religious activity & $.032(.012)$ & $.346(.098)$ & $-.135(-.049)$ & $-.489(-.139)$ & $.017(.006)$ & $-.377(-.107)$ \\
\hline Liberalism & $-.392(-.195)^{*}$ & $-.013(-.006)$ & $.070(.035)$ & $.137(.058)$ & $.253(.127)$ & $.229(.098)$ \\
\hline Christian $^{\mathrm{a}}$ & $-.798(-.180)^{*}$ & $.370(.080)$ & $-.198(-.045)$ & $-.146(-.032)$ & $.191(.043)$ & $-.072(-.016)$ \\
\hline Jewish $^{\mathrm{a}}$ & $-.785(-.156)^{*}$ & $.414(.080)$ & $.173(.034)$ & $-.559(-.108)$ & $.121(.024)$ & $-.731(-.141)$ \\
\hline Agnostic/atheist ${ }^{\mathrm{a}}$ & $-.017(-.010)$ & $.304(.168)$ & $.058(.035)$ & $-.201(-.111)$ & $.080(.048)$ & $-.234(-.129)$ \\
\hline Christian $\times$ religious activity & $.093(.028)$ & $-.208(-.051)$ & $.022(.007)$ & $.477(-.118)$ & $-.149(-.044)$ & $.370(.092)$ \\
\hline Jewish $\times$ religious activity & $.319(.109)$ & $.104(.030)$ & $-.125(-.043)$ & $.354(.100)$ & $-.196(-.067)$ & $.384(.109)$ \\
\hline Christian $\times$ liberalism & $.624(.189)^{*}$ & $.016(.004)$ & $.090(.027)$ & $-.338(-.095)$ & $-.178(-.054)$ & $-.448(-.125)$ \\
\hline Jewish $\times$ liberalism & $.628(.145)$ & $-.181(-.041)$ & $.038(.009)$ & $.128(.029)$ & $.064(.015)$ & $.143(.032)$ \\
\hline Political activity $\times$ liberalism & $.023(.021)$ & $.022(.021)$ & $-.056(-.053)$ & $-.021(-.020)$ & $-.038(-.036)$ & $.045(.042)$ \\
\hline Biological sciences $^{\mathrm{b}}$ & $-.027(-.024)$ & $-.121(-.104)$ & $.071(.062)$ & $.190(.163)$ & $-.036(-.032)$ & $.053(.045)$ \\
\hline Social sciences ${ }^{\mathrm{b}}$ & $-.016(-.012)$ & $-.217(-.163)$ & $.056(.044)$ & $.144(.108)$ & $.100(.078)$ & $.133(.100)$ \\
\hline Humanities $^{\mathrm{b}}$ & $-.058(-.052)$ & $-.260(-.233)^{*}$ & $.040(.036)$ & $-.040(-.036)$ & $.051(.046)$ & $-.030(-.027)$ \\
\hline Hard sciences ${ }^{b}$ & $.049(.044)$ & $-.276(-.238)^{*}$ & $.005(.005)$ & $.075(.065)$ & $-.158(-.143)^{*}$ & $-.075(-.064)$ \\
\hline Total $R^{2}$ & .01 & .08 & .12 & .21 & .22 & .22 \\
\hline
\end{tabular}

Semi-partial correlation reflects the unique relationship between each variable and the given scale score (entry $-N=165$; exit -105 )

${ }^{*} p<.05, * * p<.01, * * * p<.001$

a Designates dummy variable where " 1 " represents an individual of that religious affiliation

b Designates dummy variable where "1" represents an individual whose major is in that division 
Table 6 Scores, (standard deviations), and results of paired $t$ tests for the evolution literacy survey scales

Only those who responded to both the entry and exit survey are included here $(0-100$ scale, $N=121)$

$* p<.05, * * p<.01, * * * p<.001$

following two things: in general, Christians and Jews had fewer social objections to evolution than people of other religious backgrounds; liberalism was generally associated with fewer social objections, but within Christians, the opposite was true and conservatives had fewer objections. This may reflect a stronger sense in liberal Christians that evolution can be misused to rationalize prejudice against disenfranchised groups (see Cartmill 1998).

\begin{tabular}{llllc}
\hline & Entry & Exit & $t$ value & Cohen's $d$ \\
\hline Young Earth Creationist Beliefs & $2.25(1.96)$ & $2.23(1.98)$ & -.382 & -.03 \\
Embryo/Fetus Beliefs & $3.94(2.48)$ & $3.99(2.41)$ & .533 & .03 \\
Intelligent Design Fallacies & $2.88(1.88)$ & $2.82(1.84)$ & -1.162 & -.07 \\
Social Objections to Evolution & $3.35(2.12)$ & $3.67(1.19)$ & $2.998^{* *}$ & .28 \\
Factual Understanding of Evolution & $5.44(1.78)$ & $5.64(1.80)$ & $3.425^{* * *}$ & .25 \\
Relevance of Evolution & $5.50(1.88)$ & $5.83(1.95)$ & $4.461^{* * *}$ & .38 \\
\hline
\end{tabular}

The Exiting Population: Factual Understanding and Relevance of Evolution

The effects of the course on the Factual Understanding and Relevance scales were quite similar:

- Both increased over the course of the semester (Factual Understanding $-t=3.425$, Cohen's $d=.25$; Relevance$t=4.461$, Cohen's $d=.38$; see Table 6).

Table 7 Standardized betas (and semi-partial coefficients) from a two-step regression using entry scores and background variables to predict scale scores in the exit survey

\begin{tabular}{|c|c|c|c|}
\hline & Social objections to evolution & Factual understanding of evolution & Relevance of evolution \\
\hline \multicolumn{4}{|l|}{ Block one } \\
\hline Entry score $^{\mathrm{a}}$ & $.482(.387)$ & $.684(.588)^{* * *}$ & $.586(.407)^{* * *}$ \\
\hline Initial $R^{2 b}$ & .22 & .46 & .34 \\
\hline \multicolumn{4}{|l|}{ Block two } \\
\hline Class level & $.072(.060)$ & $.009(.008)$ & $.100(.082)$ \\
\hline Level of evolutionary training & $-.006(.005)$ & $-.061(-.054)$ & $-.060(-.053)$ \\
\hline Political activity & $-.212(-.185)^{*}$ & $.213(.183)^{* *}$ & $.160(.136)$ \\
\hline Religious activity & $.334(.095)$ & $-.216(-.061)$ & $-.225(-.064)$ \\
\hline Liberalism & $.092(.039)$ & $.236(.100)$ & $.161(.068)$ \\
\hline Christian $^{\mathrm{c}}$ & $.629(.135)$ & $.345(.074)$ & $.063(.014)$ \\
\hline Jewish $^{\mathrm{c}}$ & $.686(.131)$ & $-.359(-.069)$ & $-.635(-.123)$ \\
\hline Agnostic/atheist $^{\mathrm{c}}$ & $.309(.171)^{*}$ & $-.172(-.095)$ & $-.206(-.114)$ \\
\hline Christian $\times$ religious activity & $-.269(-.067)$ & $.212(.052)$ & $.247(.061)$ \\
\hline Jewish $\times$ religious activity & $-.064(-.018)$ & $.325(.092)$ & $.371(.105)$ \\
\hline Christian $\times$ liberalism & $-.195(-.054)$ & $-.587(-.163)^{* *}$ & $-.444(-.124)$ \\
\hline Jewish $\times$ liberalism & $-.380(-.085)$ & $-.139(-.031)$ & $.163(.012)$ \\
\hline Political activity $\times$ liberalism & $.030(.028)$ & $.060(.056)$ & $.081(.075)$ \\
\hline Biological sciences $^{\mathrm{d}}$ & $-.133(-.114)$ & $.203(.174)^{* *}$ & $.094(.080)$ \\
\hline Social sciences ${ }^{\mathrm{d}}$ & $-.172(-.128)$ & $.126(.095)$ & $.074(.055)$ \\
\hline Humanities $^{\mathrm{d}}$ & $-.212(-.188)^{*}$ & $-.006(-.006)$ & $-.026(-.023)$ \\
\hline Hard sciences ${ }^{\mathrm{d}}$ & $-.231(-.197)^{*}$ & $.047(.040)$ & $.015(.082)$ \\
\hline Adjusted residual $R^{2 \mathrm{e}}$ & .04 & .29 & .11 \\
\hline
\end{tabular}

Semi-partial correlation reflects the unique relationship between each variable and the given scale score $(N=105)$

${ }^{*} p<.05, * * p<.01, * * * p<.001$

${ }^{a}$ Beta represents the coefficient when the entry score is the lone predictor, the semi-partial is that from the full-model regression

${ }^{\mathrm{b}}$ Represents the variance explained by the entry score alone

${ }^{c}$ Designates dummy variable where " 1 " represents an individual of that religious affiliation

${ }^{\mathrm{d}}$ Designates dummy variable where " 1 " represents an individual whose major is in that division

${ }^{\mathrm{e}}$ Calculated by the following equation: $1-\left(\frac{d f_{e, i}}{d f_{e, f}}\right) \frac{S S E_{f}}{S S E_{i}}$, where the subscripts $i$ and $f$ indicate the value after the initial block and the final block are entered 
- The background variables that predicted different scores across groups at the beginning of the semester were no longer associated with scores in the exit population: those with less evolutionary training in high school caught up with their peers, reporting similar scores in the exit population (Factual Understanding- $\beta=.122, p=n s ;$ Relevance $-\beta=.076$, $p=n s$; see Table 5); and the lower opinion of evolution's relevance among those majoring in the physical sciences disappeared by the end of the course.

- In the exit population, higher levels of political activity were associated with higher scores in knowledge and attitudes (Factual Understanding- $\beta=.356, p<.001$; Relevance $-\beta=.278, p<.01$; see Table 5). Interestingly, although there was a small but significant correlation between one's level of political activity and placement on the conservative-liberal spectrum $(r=.221, p<.05)$, these effects are independent of ideology.

- In general, students of different religious and ideological backgrounds benefited equally from the course in terms of understanding and attitudes. The only exception was that liberalism in Christians was associated with less growth in scores on the knowledge scale $(\beta=-.587, p<.01 ;$ see Table 7$)$. This finding is somewhat counter-intuitive, but it is important to note that this does not mean that the course was ineffective in achieving this goal for liberal Christians but that it was less effective in doing so than for others.

- Across all divisions of academia, students experienced a similar rise in Relevance. Biology majors had a greater change in their Factual Understanding $(\beta=.203, p<.01$; see Table 7). This accentuation may in part be owed to such students taking multiple biology classes simultaneously.

\section{The Exiting Population: Objections to Evolution}

Reports of Young Earth Creationist, Embryo/Fetus and Intelligent Design beliefs did not change over the course of the semester (respectively $t=-.382$, Cohen's $d=-.03$; $t=.553$, Cohen's $d=.03 ; t=-1.162$, Cohen's $d=-.07$; see Table 6). Regarding this null result, it is worth noting that the scores on each, particularly the Young Earth Creationist scale, were quite low to begin with. On the other hand, there was a rise in Social Objections to evolution $(t=2.998$, Cohen's $d=.28$; see Table 6), an unexpected effect whose meaning will be discussed below. In relation to background variables, those with a greater level of political activity experienced a lesser increase in social objections $(\beta=-.212$, $p<.05)$, as did students majoring in the humanities $(\beta=-.212, p<.05)$ and physical sciences $(\beta=-.231$, $p<.05)$. Individuals who self-reported being agnostic or atheist, however, experienced a greater increase in social objections than their classmates $(\beta=.309, p<.05)$.

The increase in Social Objections, combined with the increase in Relevance and Factual Understanding, suggest that not only has the course instilled the students with a better understanding of evolution but also a nuanced sense of how any theory can be misused. Additionally, while the entry scores on factual understanding explained $35 \%$ of the variation in exit scores, the entry scores on the other two scales only explained $\sim 15 \%$ of the variation in their respective exit scores, meaning the two measurements were largely independent of each other. Thus, the change in attitudes we observed was not one of a uniform increase, with individuals maintaining the same level of support or skepticism, relative to their classmates. On the contrary, the course was capable of influencing both skeptics and supporters to reconfigure their conception of evolutionary theory's applications in a thoughtful, sophisticated manner.

\section{Conclusions and Future Directions}

Our entry survey supports previous research showing that a strong focus on evolutionary theory in high school is influential in increasing its acceptance (Moore and Cotner 2009; Hawley et al. 2009); however, college biology courses often report being unable to affect such change on a broad scale (e.g., Martin-Hansen 2008; Moore and Cotner 2009; Robbins and Roy 2007). The long-lasting implications of such shortcomings in higher education are striking: even a sizable proportion of high school biology teachers in America are proponents of creationism and Intelligent Design (for a national study, see Berkman et al. 2008; for a review of single-state studies, see Donnelly and Boone 2007). Given these difficulties within the life sciences, it would seem that the task stated here-to educate students from all disciplines in evolution-would be particularly daunting. On the contrary, "Evolution for Everyone" successfully communicated the importance of evolution in a large lecture setting, thoroughly integrating human-related material with more standard biological material.

Including human-related material engages non-biologists and gives biology students a new perspective on an old topic. Understanding and acceptance of evolution increased uniformly across the disciplines (discounting the artifactual additional increase in understanding experienced by biology majors during the semester), and there was no visible difference between them in the outgoing population. There was variation across disciplines in the amount of change in social objections; however, even this result was satisfying. Students studying in the humanities experienced a smaller rise in social objections than their peers, which is particularly interesting given that these very disciplines at 
times reject evolutionary theory on such bases (Gottschall 2008).

While the different perspectives associated with academic disciplines are one challenge the course hoped to overcome, those associated with religion and political ideology also pose a clear and present difficulty. Interestingly, no political or religious ideal was associated with resistance to evolutionary theory at either the beginning or end of the semester. This finding seems odd but may reflect a lack of evangelical Christians on B.U.'s campus; it is also possible that those few students who are evangelicals are unlikely to enroll in this course. That notwithstanding, it is impressive to note that the increased acceptance of evolution was consistent across all religious denominations and political ideologies. This stood true as well for politically active students, the greatest beneficiaries of the course.

It stands to reason that evolution can be effectively conveyed to people of all backgrounds, provided it is not presented in a way that is seen as an attack on their other beliefs. This does not mean, however, that the topic should be avoided altogether, simply that it should be treated respectfully. One lecture even focused on the evolution of religion, describing and testing the extant hypotheses in a manner that did not criticize religion as a societal institution. In fact, the correlation between conservative religious beliefs and acceptance of evolution is not an international rule (Miller et al. 2006), and the two should not be viewed as mutually exclusive. The same study found that even Americans are almost twice as likely $(76 \%$ to $40 \%$ ) to say that evolution is true if the process of natural selection is described to them without using the words "evolution" or "Darwin." The explanatory power of evolutionary theory, when demonstrated in an unthreatening manner, makes it an enticing option. As an anecdotal example, after learning about pregnancy sickness from an evolutionary perspective, a female student wrote that "Even though I don't believe in evolution, I'm glad to know that Darwin's theory can explain why I might get sick during pregnancy." While this statement itself makes no logical sense, it reflects how the class' material was able to open a mind that was previously closed to evolutionary theory. This effect may also explain why politically active individuals absorbed the most from the course, intrigued by its application to their passion for human affairs. Simply put, natural selection is an algorithm, as undeniable as algebra or Newtonian physics, and if conveyed with a sensitivity for cultural differences, people cannot help but acknowledge its explanatory scope.

Because the course is part of the larger EvoS program, the students have the ability to reorient their future studies to expand on the sophisticated scientific views with which they leave the course - and can do so regardless of their major of study. Many alumni of the course have subsequently joined the EvoS Program, committing to the pursuit of a certificate in evolutionary studies. Additionally, approximately $20 \%$ of the students from each year's course apply to be teaching and research assistants for the following year.

The EvoS Consortium also provides the infrastructure to improve and expand on the course's success through intercollegiate cooperation. We have explicitly designed the course to be implemented at other institutions, either by itself or as part of a multi-course EvoS program. The modular format gives each instructor flexibility to design their course as they see fit while making use of material developed elsewhere. Coordination across institutions offers many advantages: instructors can collaborate on teaching techniques; experiments can be used to illustrate not only within-class variation but cultural variation among many universities. To this end, the syllabus, lectures, and other course-related materials we have developed will soon be available online on the EvoS consortium website (http:// www.evostudies.org), a centralized bank that can grow as the course is taught by an increasing number of educators. A guide to organizing similar courses will be published as a companion to this paper in the newly launched EvoS Journal (http://www.evostudies.org/journal.html). These resources will enable educators to select the materials and techniques that they would like to employ when teaching evolutionary theory.

In its current form at B.U., Evolution for Everyone represents a successful experiment in evolution education, one that attempts to engage students of all academic and personal backgrounds in evolutionary studies. Focusing on human affairs and an interactive approach, the material is accessible and intriguing to students of all academic and personal backgrounds. The large, diverse population taking the course took the first steps to becoming, if not actual scientists, purveyors of scientific thought in their everyday lives. We hope to export the course in an effort to replicate not so much its curriculum but its ideals: to give all undergraduates the skills necessary to ask questions about their world and answer them effectively.

Acknowledgments We would like to extend special thanks to participants of B.U.'s EvoS program and SUNY New Paltz's EvoS program, in addition to Craig Nelson and Brian Alters serving as advisors during the formation of EvoS. We also thank the National Science Foundation for funding the expansion of this class' goals as well as the infrastructure that will permit its exportation.

\section{References}

Berkman MB, Pacheco JS, Plutzer E. Evolution and creationism in America's classrooms: a national portrait. Public Libr Sci. 2008;6:920-4. 
Boehm C. Hierarchy in the forest: the evolution of egalitarian behavior. Cambridge: Harvard University Press; 2001.

Bowles S. Microeconomics: behavior, institutions, and evolution. Princeton: Princeton University Press; 2006.

Bowles S. Policies designed for self-interested citizens may undermine "The Moral Sentiments": evidence from economic experiments. Science. 2008;320:1605-9.

Bressler ER, Martin RA, Balshine S. Production and appreciation of humor as sexually selected traits. Evol Hum Behav. 2006;27:121-30.

Bshary R, Noë R. Biological markets: the ubiquitous influence of partner choice on the dynamics of cleaner fish-client reef fish interactions. In: Hammerstein P, editor. Genetic and cultural evolution of cooperation. Cambridge: MIT Press; 2003. p. 16784.

Buller DJ. Adapting minds: evolutionary psychology and the persistent quest for human nature. Cambridge: The MIT Press; 2006.

Burks S, Carpenter J, Goette L, Monaco K, Porter K. Using behavioral economic field experiments at a firm: the context and design of the truckers and turnover project. In: Bender S, Lane J, Shaw K, Andersson F, von Wachter T, editors. The analysis of firms and employees. Chicago: The University of Chicago Press; 2008. p. 45-106.

Buss DM. Evolutionary psychology: the new science of the mind. Boston: Pearson Education; 2004.

Cartmill M. Oppressed by evolution. Disc. 1998;19:78-83.

Coalition of Scientific Societies (CSS). You say you want an evolution? A role for scientists in science education. Available at http://opa.faseb.org/pages/PolicyIssues/sciencecoalition.htm (Accessed on June 10, 2009).

Darwin C. The origin of species. New York: Signet Classics; 1859/2003.

Davis P, Kenyon DH. Of pandas and people: the central question of biological origins. Richardson, TX: Foundation for Thought and Ethics; 1993.

Donnelly L, Boone WJ. Biology teachers' attitudes toward and use of Indiana's evolution standards. J Res Sci Teach. 2007;44:236-57.

Dunbar R, Barrett L, Lycett J. Evolutionary psychology: a beginner's guide. Oxford: Oneworld; 2005.

Gallup AC, O'Brien DT, White DD, Wilson DS. Peer victimization in adolescence has different effects on the sexual behavior of male and female college students. Pers Indiv Differ. 2009;46:611-5.

Garcia JR, Reiber C. Hook-up behavior: a biopsychosocial perspective. J Soc Evol Cult Psychol. 2009; Proceedings of the 2nd annual meeting of the NorthEastern Evolutionary Psychology Society: 49-65.

Gardiner LF. Why we must change: the research evidence. Thought Action. 1998;14:71-88.

Geher G, Kaufman SB. The Mating Intelligence scale. Psychol Today. 2007;40:78-9.

Gintis H. Five principles for the unification of the behavioral sciences. Brain Behav Sci. 2007;30:1-61.

Gintis H, Bowles S, Boyd R, Fehr E. Moral sentiments and material interests. Cambridge: MIT Press; 2005.

Gottschall J. Literature, science and a new humanities. New York: Palgrave Macmillan; 2008.

Gould SJ. Evolution as fact and theory. Discover. 1981;May:34-7.

Gould SJ, Lewontin RC. The spandrels of San Marco and the Panglossian paradigm: a critique of the adaptationist programme. Proc R Soc Lond B. 1979;205:581-595.

Haidt J. The happiness hypothesis: finding modern truth in ancient wisdom. New York: Basic; 2006.

Hawley PH, Parkinson H. Evolutionary attitudes and literacy survey. Unpublished instrument, beta version 1.0. University of Kansas, Lawrence, KS. 2008.
Hawley PH, Little TD, Sunderland TR, Mendoza CM. What's the matter with Kansas? Psychometric validation of the Evolutionary Attitudes and Literacy Survey. Presentation at the Human Behavior and Evolution Society Annual Meeting, Fullerton, California. May, 2009.

Henrich J, Boyd R, Bowles S, Camerer C, Fehr E, Gintis H, eds. Foundations of human sociality. Oxford: Oxford University Press; 2007.

Kettlewell HBD. Selection experiments on industrial melanism in the Lepidoptera. Heredity. 1955;9:323-42.

Lamarck JB. Zoological philosophy: exposition with regard to the natural history of animals. Chicago: University of Chicago Press; $1809 / 1984$.

Leenaars LS, Dane AV, Marini ZA. Evolutionary perspective on indirect victimization in adolescence: the role of attractiveness, dating and sexual behavior. Agg Behav. 2008;34:404-15.

Lombrozo T, Thanukos A, Weisberg M. The importance of understanding the nature of science for accepting evolution. Evol Educ Outreach. 2008;1:190-8.

Martin-Hansen LM. First-year college student's conflict with religion and science. Sci Educ. 2008;17:317-57.

Mayor A. The first fossil hunters: paleontology in Greek and Roman times. Princeton: Princeton University Press; 2001.

Miller JD, Scott EC, Okamoto S. Public acceptance of evolution. Science. 2006;313:765-6.

Moore R, Cotner S. Educational malpractice: the impact of including creationism in high school biology courses. Evol Educ Outreach. 2009;2:95-100.

Nettle D, Clegg H. Schizotypy, creativity and mating success in humans. Proc R Soc B. 2006;273:611-5.

Numbers RL. The creationists: from scientific creationism to Intelligent Design (expanded edition). Cambridge: Harvard University Press; 2006.

Parliamentary Assembly of the Council of Europe (PACE). The dangers of creationism in education. Available at: http://www. assembly.coe.int/Main.asp?link=/Documents/WorkingDocs/ Doc07/EDOC11297.htm (accessed April 22, 2009).

Paz-y-Miño G, Espinosa A. Assessment of biology majors' versus nonmajors' views on evolution, creationism, and intelligent design. Evol Educ Outreach. 2009;2:75-83.

Pinker S. The blank slate: the modern denial of human nature. New York: Viking; 2002.

Robbins JR, Roy P. The natural selection: identifying and correcting nonscientific student preconceptions through an inquiry-based, critical approach to evolution. Am Biol Teach. 2007;69:460-6.

Rutledge M, Mitchell M. High school biology teachers' knowledge structure, acceptance and teaching of evolution. Teach Evol. 2002;64:21-8

Saucier G. Mini-markers: a brief version of Goldberg's unipolar Big Five markers. J Pers Assess. 1994;63:506-16.

Scharmann LC, Harris WM. Teaching evolution: understanding and applying the nature of science. J Res Sci Teach. 1992;29:375-88.

Spiegel AN, Evans EM, Gram W, Diamond J. Museum visitors' understanding of evolution. Museum Soc. 2006;1:69-86.

Thurstone LL. The vectors of the mind. Psych Rev. 1934;41:1-32.

Verhey SD. The effect of engaging prior learning on student attitudes toward creationism and evolution. Bioscience. 2005;55:9961003.

Wilson DS. Evolution for everyone: how to increase acceptance of, interest in, and knowledge about evolution. Public Libr Sci. 2005;3:1001-8.

Wilson DS. Evolution for everyone. New York: Bantam Dell; 2007.

Woods CS, Scharmann LC. High school students' perceptions of evolutionary theory. Elec J Sci Educ. 2001;6:Article 3. 